\title{
Experimental Study on Predicting Service Life of Concrete in the Marine Environment
}

\author{
Wenge Chai ${ }^{1}$, Wenli $\mathrm{Li}^{2,4, *}$ and Hengjing $\mathrm{Ba}^{3}$ \\ ${ }^{I}$ The North China University of Technology, Beijing 100144, China \\ ${ }^{2}$ School of Mechanics \& Civil Engineering, China University of Mining \& Technology, Beijing Campus, Beijing \\ 100083, China \\ ${ }^{3}$ School of Civil Engineering, Harbin Institute of Technology, Harbin 150006, China \\ ${ }^{4}$ City Construction Department, Beijing City University, Beijing 100083, China
}

\begin{abstract}
In this paper, the corrosion of steel during the accelerated corrosion test was investigated through linear polarization method. The critical chloride ion concentration was determined according to the mentioned experimental results. Through the analysis of the experimental results of accelerated penetration test, the service life prediction equation of concrete structures was established. The $20 \mathrm{~V}$ predicted results exhibited good compliance with the measured values, which indicated the reasonableness of the mentioned prediction method.
\end{abstract}

Keywords: Concrete, Accelerated Permeability Test, Service Life Prediction.

\section{INTRODUCTION}

Many costly important constructions in the marine environment have been built or are under construction, such as sea-crossing bridges, submarine tunnels, offshore oil production platforms, harbors, and offshore projects, etc. The durability of concrete structures in the marine environment has become a hotspot in the civil engineering.

For lack of attention to the durability in design, many completed concrete constructions have to cost a lot in repair and reinforcement to maintain their regular services. Therefore, durability service life prediction shall be put on the agenda [1]. Correct evaluation and accurate prediction of concrete service life under the chloride ion environment are the essential orientation of concrete durability research. There are many studies on concrete service life prediction models based on chloride ion permeability [1-7]; these studies mainly predict the service life of saturate concrete under the condition that the chloride ion in the concrete works on the corrosion of steel (generally means induction period service life) by applying Fick Second Law of Diffusion.

Concrete is the porous material composed of solid phase and liquid phase; in addition to the chemical bond ability and interionic interaction, cationic lag movement and double electronic layers formed on the solid surface will have significant effects on diffusion behavior of chloride ions, so diffusion behavior of chloride ions in concrete is a

*Address correspondence to this Author at the City Construction Department, Beijing City University, Beijing 100083, China;

Tel: +86-13161328262; Fax: +86-10-62322615;

E-mails: liwenli@bcu.edu.cn, lidi66@sohu.com comprehensive and extremely intricate transmission process. Therefore, it is inappropriate to adopt Fick Law to describe the transmission performance of chloride ion in concrete [2], and it is of great importance to find an easy and practicable method that can predict concrete service life.This paper adopts the accelerated life test to make durability evaluation and service life prediction of concrete structure under the chloride ion environment.

In the process of durability evaluation and service life prediction of concrete structures under the chloride ion environment, the critical value in the depassivation of steel is a pivotal question [3]. Concrete service life in this paper means the period from the initial use to depassivation or to the corrosion of steel; the critical chloride ion concentration is considered as the criterion of concrete service life ending, that is to say, when the chloride ion concentration on the steel surface reaches the critical value, the concrete service life is considered to end.

\section{TEST SCHEME}

The two experiments were carried out: critical chloride ion concentration test and concrete service life prediction test. In the experiments, there are two groups of concrete specimens.

Groupe 1: Water cement ratio is 0.48 . The amount of raw materials for concrete per cubic meter: ordinary portland cement $370 \mathrm{~kg}$, sand $795 \mathrm{~kg}$, gravel $1064 \mathrm{~kg}$, water $177.6 \mathrm{~kg}$ and water reducer $1.11 \mathrm{~kg}$.

Groupe 2: The concrete was manufactured in the same raw materials and mix proportion as the concrete of the sea wall at Qingdao which was 14 years old. Water cement ratio is 0.48 . The amount of raw materials for concrete per cubic 
meter: ordinary portland cement $259 \mathrm{~kg}$, fly ash (FA) $74 \mathrm{~kg}$, slag $37 \mathrm{~kg}$, sand $795 \mathrm{~kg}$, gravel $1064 \mathrm{~kg}$, water $177.6 \mathrm{~kg}$ and water reducer $1.11 \mathrm{~kg}$.

\subsection{Critical Chloride Ion Concentration Test Scheme}

Moulding $\varphi 100 \mathrm{~mm} \times 100 \mathrm{~mm}$ specimen (refer with: Fig. 1). When moulding the specimen, the core is embedded into a surface-polished $\varphi 10 \mathrm{~mm} \mathrm{Q235} \mathrm{round} \mathrm{steel,} 80 \mathrm{~mm}$ long, and the area of exposure is $25.1 \mathrm{~cm}^{2}$. The embedded reference electrode self-made in the laboratory is embedded into the place $10 \mathrm{~mm}$ from the reinforcing steel. After 28 days' standard curing, the specimen is vacuum watersaturated according to ASTMC1202, and then the linear polarization method is adopted to measure the polarization resistance $(\mathrm{Rp})$ of the steel. The test system is shown in Fig. (2). When the polarization resistance is lower than $25 \mathrm{k} \Omega \cdot \mathrm{cm}^{2}$, the steel is considered to be of full deterioration.

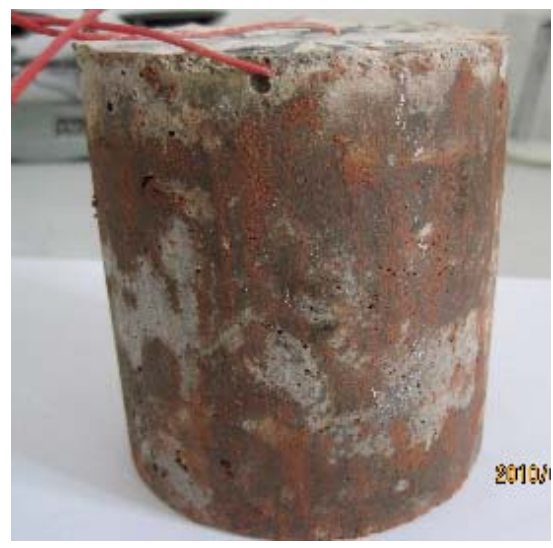

Fig. (1). Concrete specimen.

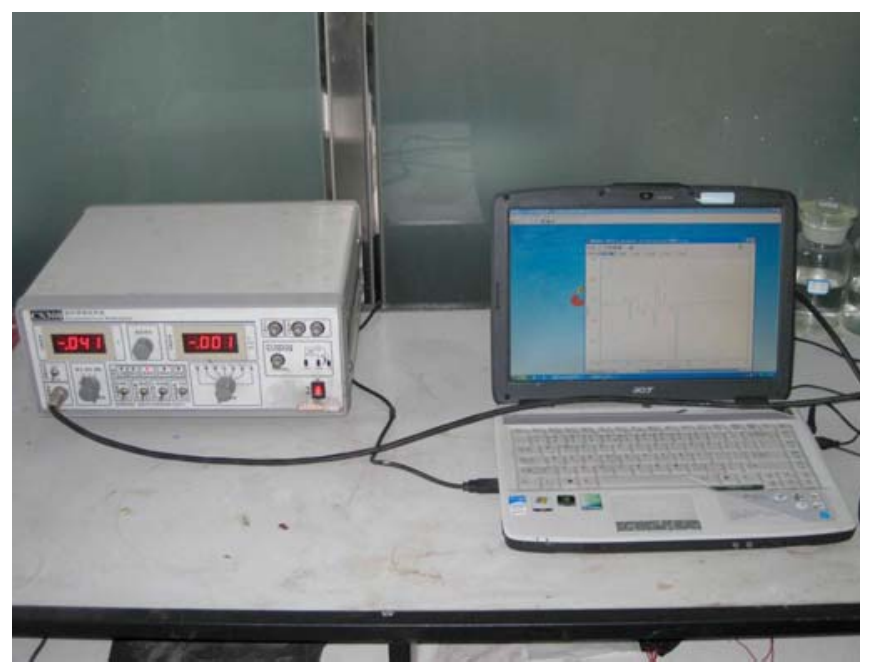

Fig. (2). Linear polarization method measurement system.

Fig. (3) is the diagram of accelerated corrosion permeability test of chloride ion. In the figure, $3 \% \mathrm{NaCl}$ solution is in the cathode chamber, and $0.3 \mathrm{~mol} / \mathrm{L} \mathrm{NaOH}$ solution is in the anode chamber. After $24 \mathrm{~h}$ acceleration and then $24 \mathrm{~h}$ rest, the polarization resistance is measured, which is a test period. The accelerated test is terminated until the complete degradation of the steel.

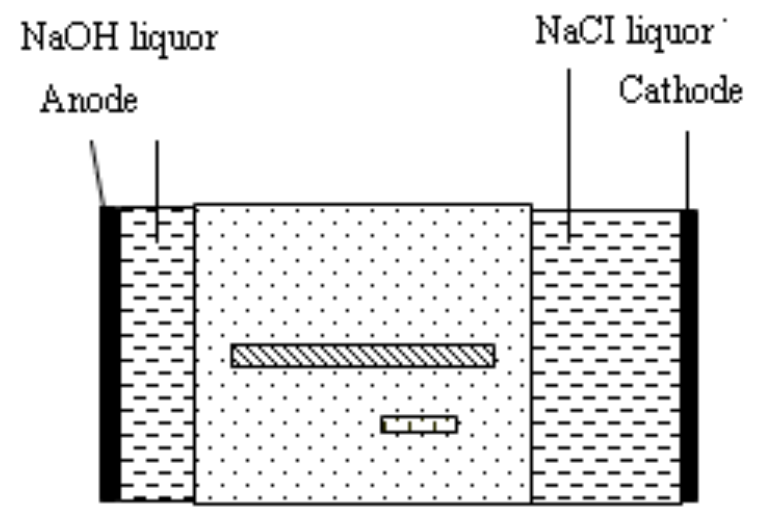

Fig. (3). Steel accelerated corrosion test device.

The voltage caused by the differential concentration of chloride ion is the driving force for chloride ion permeability of underwater concrete, so different external voltages are selected to proceed with the accelerated permeability test. In consideration of the test time and overhigh voltage causing electrolytic reaction, the added direct-current voltages of $20 \mathrm{~V}, 12 \mathrm{~V}, 6 \mathrm{~V}$ and $3 \mathrm{~V}$ are selected to make steel accelerated corrosion test to determine the reasonable accelerated voltage and further define the chloride ion content in concrete under the reasonable voltage is the critical concentration of steel corrosion in concrete.

\subsection{Test Scheme of Concrete Service Life Prediction}

Moulding $\varphi 100 \times 300 \mathrm{~mm}$ column specimen. After 28 days' standard curing, the column specimen is cut into $50 \mathrm{~mm}$ thick specimens, which will then undergo the accelerated permeability test after being waterlogged under vacuum. In the test, the $0.5 \mathrm{~mol} / \mathrm{L} \mathrm{NaCl}$ solution is in the cathode chamber, and $0.3 \mathrm{~mol} / \mathrm{L} \mathrm{NaOH}$ solution is in the anode chamber. Generally, the thickness of protective layer of the steel is $4.5 \mathrm{~cm}$, so sample powders are drilled from concrete in the place $4-5 \mathrm{~cm}$ from the interface between the anode chamber solution and the concrete to measure the chloride ion content.

\section{TEST RESULT AND ANALYSIS}

\subsection{Determination of Critical Chloride Ion Concentration}

The test result indicated (as shown in Fig. 4) that at $20 \mathrm{~V}$ accelerating voltage, chloride ions rapidly permeate to the steel surface. Polarization resistance $\mathrm{Rp}$ of the steel has begun to lower significantly at $2 \mathrm{~d}$; Rp value of the steel is lower than $25,000 \mathrm{Ohm}$ at $8 \mathrm{~d}$; the passivation membrane of the steel is completely degraded. The hardened cement powders at the interface of steel corrosion are obtained, and the powders samples are processed according to the water dissolution of Testing Code of Concrete For Port and Waterway Engineering (JTJ270-98 in Chinese). As a result, the average content of chloride ions of the specimens is measured: $1.238 \%$ for group $1,1.321 \%$ for group2. 


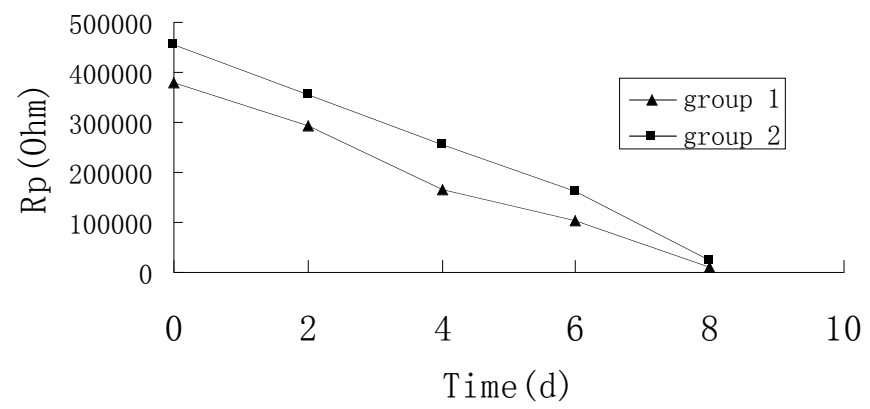

Fig. (4). Curve of Rp with time at $20 \mathrm{~V}$.

In Fig. (5), Rp value gradually lessens, and before $2 d$, Rp value decreases slightly; after $2 \mathrm{~d}$, $\mathrm{Rp}$ value decreases sharply, which is because before $2 \mathrm{~d}$, in the process of entering into concrete, chloride ions haven't reached the steel surface, when the $\mathrm{Rp}$ value reflects the entire ability of resistance of the depassivating film of the steel surface and concrete resistance to corrosion. After 2d, chloride ions have permeated to the steel surface and the depassivating film has started to degrade, causing the sharp decrease of the Rp value.

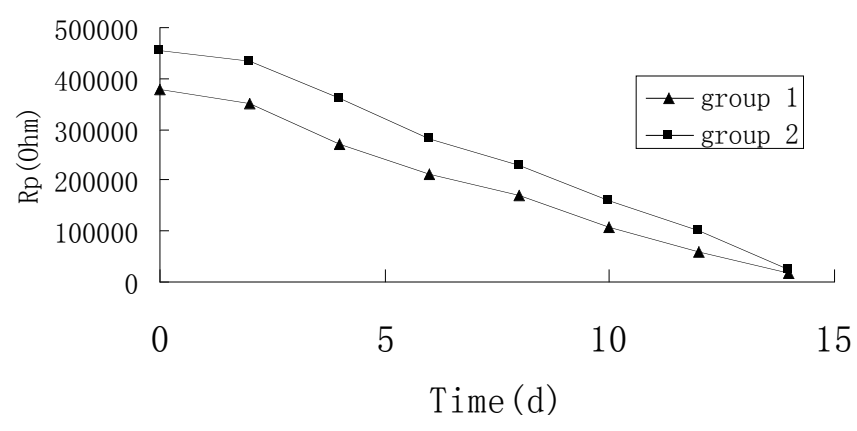

Fig. (5). Curve of $\mathrm{Rp}$ with time at $12 \mathrm{~V}$.

Due to the short permeation time of chloride ions in concrete, the chloride ions gathered at the steel surface exceed the critical chloride ions concentration of steel depassivation in the process of sustained accelerated permeation. Therefore, the accelerated voltage shall continue to be decreased. At $12 \mathrm{~V}$, the average chloride ion content of the specimens in group 1 and group 2 at the corrosion place of the steel is $0.823 \%$ and $0.882 \%$ respectively.

It can be observed from Fig. (6) and Fig. (7) that, in company with decrease of accelerated voltage, the time of chloride ion permeating to the steel surface gets longer and longer. The Rp curve at accelerated voltage $3 \mathrm{~V}$ presents an ideal preliminary platform region, namely, the process of chloride ions gathering near to the steel from the exterior agrees with the actual natural permeating conditions. The average chloride ion contents at $6 \mathrm{~V}$ at the corrosion place of the steel in group 1 and group 2 are $0.493 \%$ and $0.482 \%$ respectively. At $3 \mathrm{~V}$, the average chloride ion content of the specimens in group 1 and group 2 at the corrosion place of the steel is $0.485 \%$ and $0.461 \%$ respectively.

Shown as in Fig. (4) - Fig. (7), Rp value in group 2 is higher than that of group 1. It indicates that mineral admixtures in concrete can protect passivation film of rebar and improve the resistance to corrosion of steel rebar.
Mineral admixtures decrease the content of free chloride ions due to absorbing or solidifying a large number of free chloride ions in concrete.

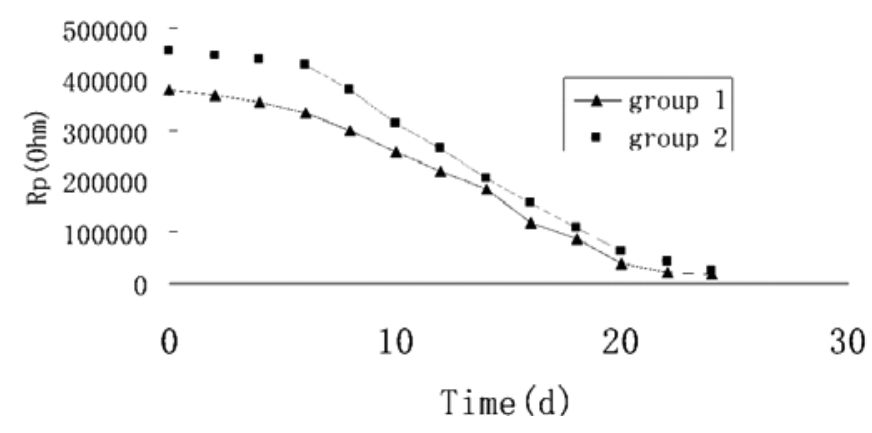

Fig. (6). Curve of Rp with time at 6V.

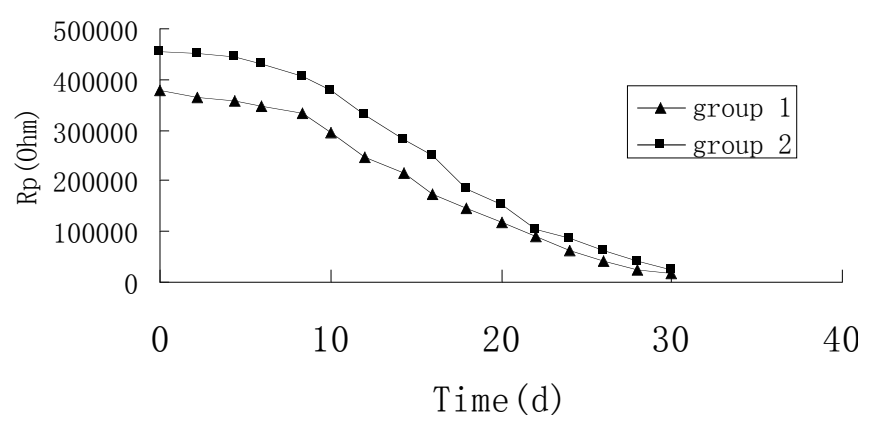

Fig. (7). Curve of $\mathrm{Rp}$ with time at $3 \mathrm{~V}$.

At $20 \mathrm{~V}$ and $12 \mathrm{~V}$, the average chloride ion content of the specimens in group 2 is higher than in group 1.The reason was that there are two forms of $\mathrm{Cl}^{-}$in concrete. One type of $\mathrm{Cl}^{-}$is in the form of $3 \mathrm{CaO} \cdot \mathrm{Al}_{2} \mathrm{O}_{3} \cdot \mathrm{CaCl}_{2} \cdot 10 \mathrm{H}_{2} \mathrm{O}$, namely Friede salt [4] or in the form of adsorbed substance in the cement hydrate or unhydrated mineralogical composation. The other type of $\mathrm{Cl}^{-}$is free, and exist in pore solution. Only reaching at some critical concentration, the free $\mathrm{Cl}^{-}$is corrosive to rebar surface. The lower Free $\mathrm{Cl}^{-}$content in concrete specimens, the less harm to concrete or rebar. It reflects that mineral admixture can decrease content of free chloride ion and hydroxide ion, as well as mass loss of rebar.

At $6 \mathrm{~V}$ and $3 \mathrm{~V}$, shown as in Fig. (6), Fig. (7), the average chloride ion content of the specimens in group 2 is lower than in group 1. The packing role and pozzolanic effects of minerals admixtures are mainly responsible for the improvement of resistance to penetration of chloride ions into concrete. It reflects that the resistance to penetration of chloride ions into concrete can be evidently improved by combining FA with slag added into concrete, and the important technical way to prepare the concrete with low penetration of chloride ions is the addition of the composite of fly ash and slag taking account of all factors.

Fig. (8) indicates the corrosion status of the steel in concrete after test. It is observed that the corrosion places of the steel are in the end of the steel near $\mathrm{NaCl}$ solution.

Fig. (9) indicates the corresponding change trend of chloride ion content when the steel surface begins to corrode after accelerated corrosion tests at different voltages. From the figure it can be observed that, at $6 \mathrm{~V}$ and $3 \mathrm{~V}$, 
corresponding critical chloride ion contents are relatively close; in company with rise of accelerated voltage, the critical chloride ion contents increase, because the voltage in the test is the driving force for chloride ion permeating into internal concrete, and higher voltage leads to bigger driving force, so under higher voltages, the chloride ions can reach the steel surface rapidly. As time prolonging, more and more chloride ions gathering at the steel surface aggravates the corrosion reaction of the steel. Meanwhile, chloride ions gather at the steel surface too fast, but the depassivation of steel requires a period, so too fast accelerated permeation process causes the result that the steel has not depassivated but the chloride ions have exceeded the critical chloride ion concentration of natural permeation. Therefore, the chloride ion contents under higher accelerated voltages are unable to reflect the critical chloride ion concentration value when steel corrodes actually. Finally, the chloride ion content at $3 \mathrm{~V}$ is selected to be the critical chloride ion concentration.

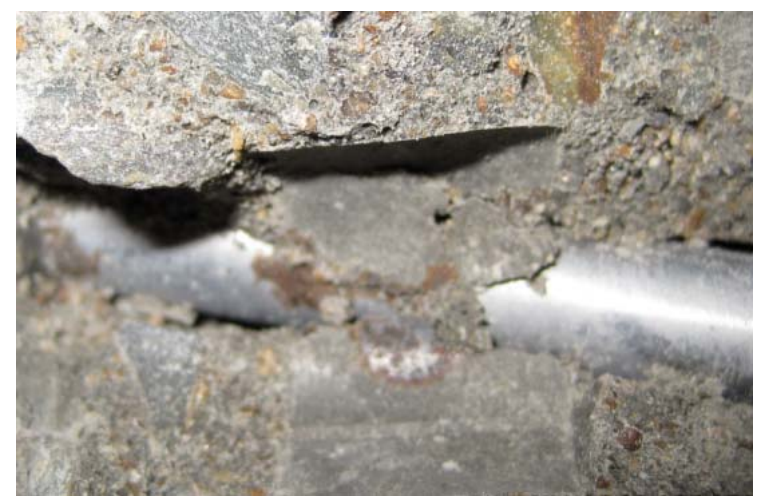

Fig. (8). Steel corrosion after test.

\subsection{Analysis on Concrete Service Life Prediction}

In the natural environment, there are three mechanisms for chloride ions to enter the concrete [5]: permeation, diffusion and capillary adsorption. Actually, the concrete structure is always invaded by chloride ions under the combination of above mechanisms; yet, one mechanism plays a leading role and in most cases, it is the diffusion [6]. As for the concrete under the seawater, the chloride ion concentration under seawater is higher than that in concrete; the differential concentration causes diffusion of chloride ions, namely, the differential concentration is the driving force of diffusion of chloride ions of underwater concrete.

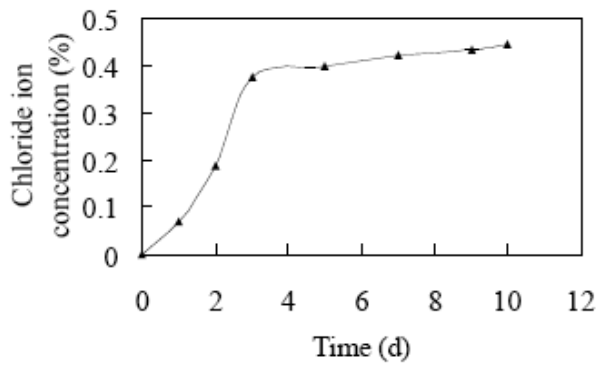

(a) group 1
As for chloride ions, there is a linear relationship between pCI (negative LOG of its molar concentration) and potential of concentration [7] (Fig. 10). The chloride ion concentration under seawater is $19 \mathrm{~g} / \mathrm{L}$ and after the conversion, the differential concentration voltage of chloride ions diffusion in concrete under seawater is $4.99 \mathrm{mV}$.

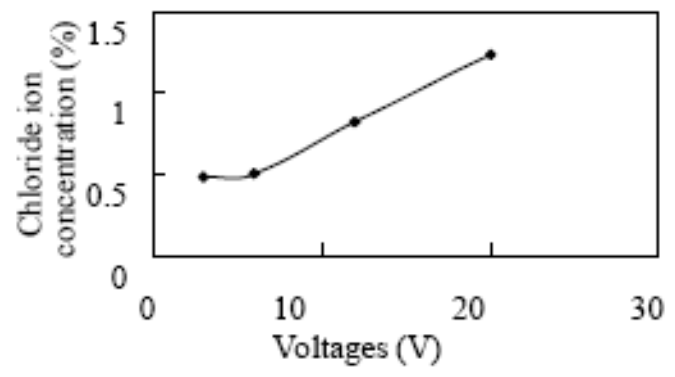

Fig. (9). Chloride ion concentrations in various voltages.

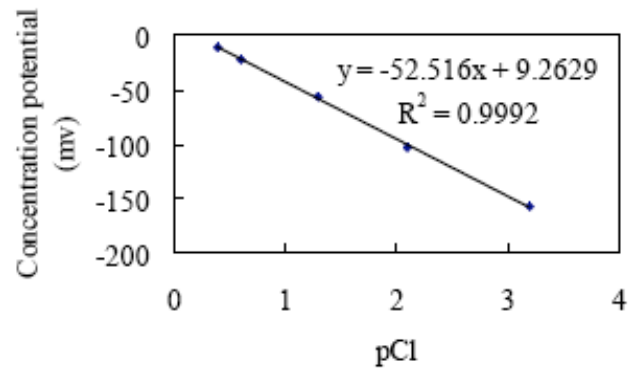

Fig. (10). Relationship of $\mathrm{pCl}$ and Concentration potential.

Under the action of $20 \mathrm{~V} \mathrm{DC}$, the chloride ions contents of concrete in the depth of $4-5 \mathrm{~cm}$ at $1 \mathrm{~d}, 2 \mathrm{~d}, 3 \mathrm{~d}, 5 \mathrm{~d}, 7 \mathrm{~d}, 9 \mathrm{~d}$ and $10 \mathrm{~d}$ are measured respectively. As shown in Fig. (11), the chloride ion content increases rapidly before $3 \mathrm{~d}$, but increases gently after $3 \mathrm{~d}$. Therefore, to facilitate the nextstage test, in other accelerated tests, the chloride ion contents in concrete at $3 \mathrm{~d}, 5 \mathrm{~d}, 7 \mathrm{~d}, 9 \mathrm{~d}$ and $10 \mathrm{~d}$ will be measured only.

From Fig. (12) to Fig. (15), it can be observed that the chloride ions contents after $3 \mathrm{~d}$ present linearity increase with time, and the fitting equation about chloride ion content with time is worked out according to the curve as shown in the figures. The necessary time of chloride ion content reaching to critical chloride ion concentration can be got through the equations thereof, as shown in Tables $\mathbf{1}, \mathbf{2}$.

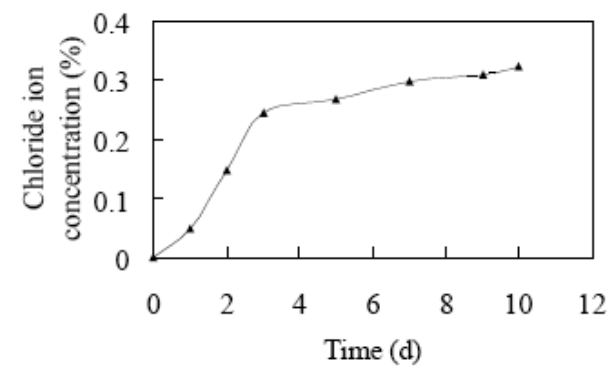

(b) group 2

Fig. (11). Relationship of concrete chloride ion concentration and time at $20 \mathrm{~V}$. 


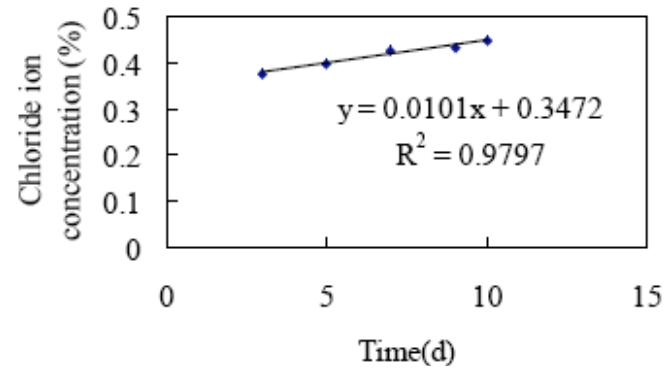

(a) group 1

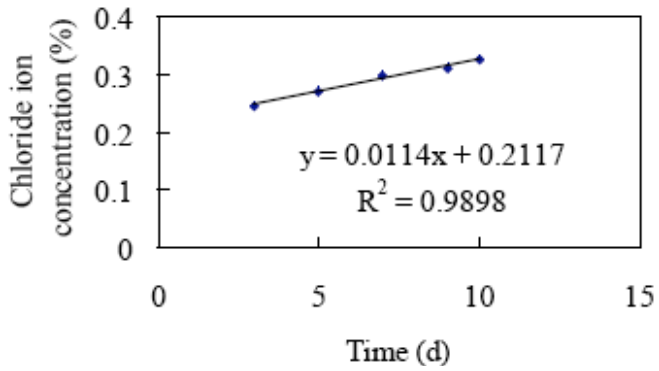

(b) group 2

Fig. (12). Accelerated life test of concrete at $20 \mathrm{~V}$.

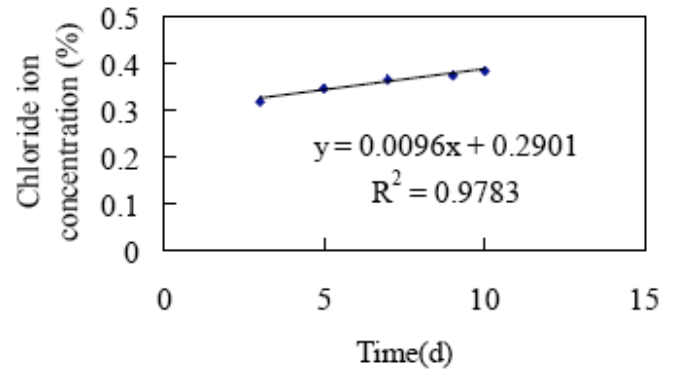

(a) group 1

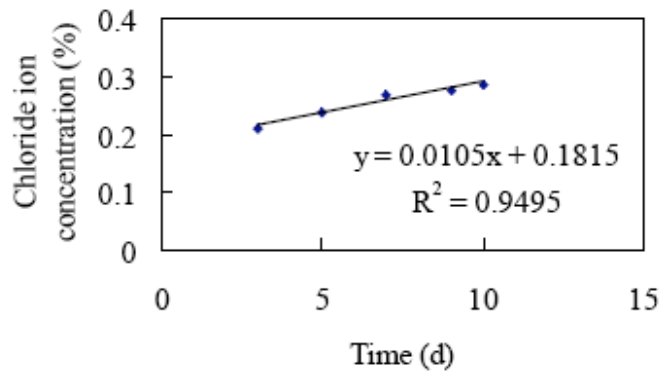

(b) group 2

Fig. (13). Accelerated life test of concrete at $12 \mathrm{~V}$.

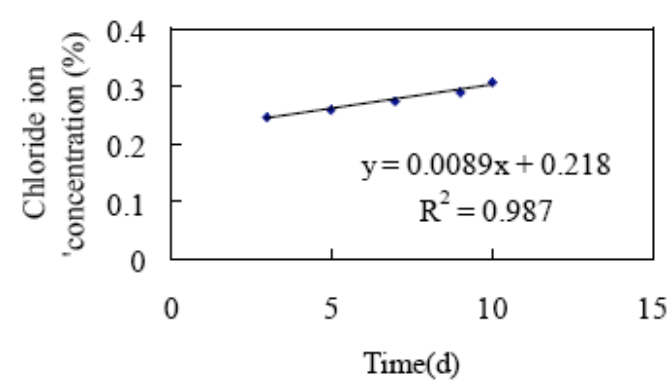

(a) group 1

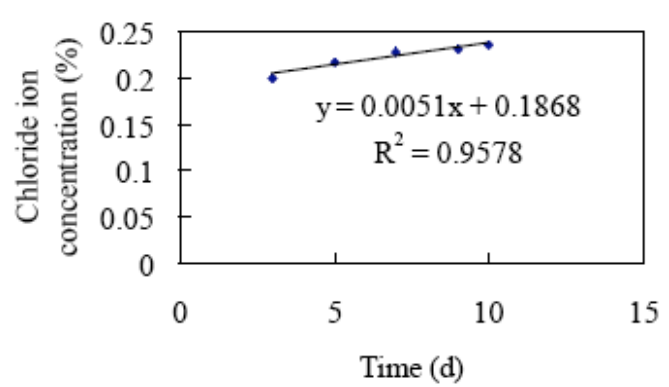

(b) group 2

Fig. (14). Accelerated life test of concrete at $6 \mathrm{~V}$.

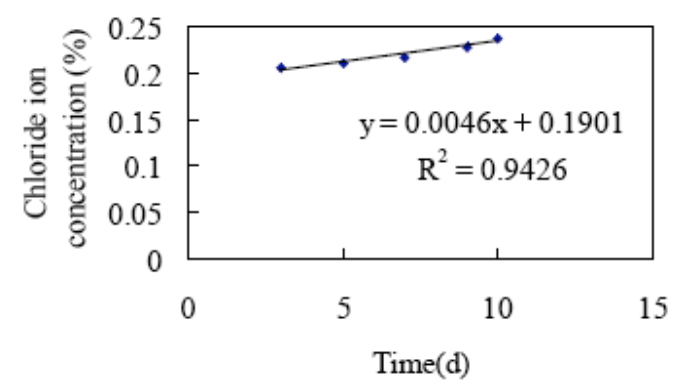

(a) group 1

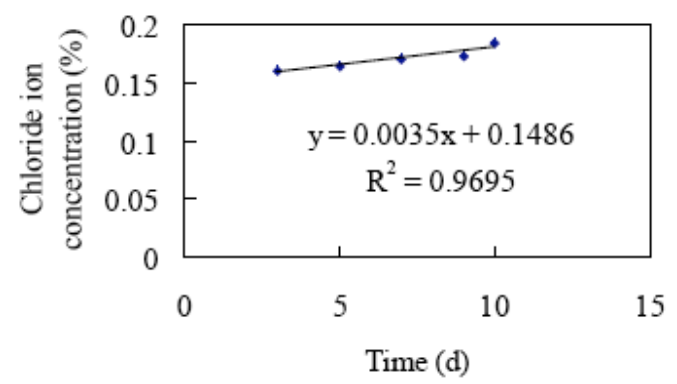

(b) group 2

Fig. (15). Accelerated life test of concrete at $3 \mathrm{~V}$. 
Table 1. Group1 Concrete Service Life at Various Voltages

\begin{tabular}{|l|c|c|c|c|}
\hline External voltage $[\mathrm{V}]$ & 20 & 12 & 6 & 3 \\
\hline Time for reaching critical concentration [d] & 13.64 & 20.3 & 30 & 64.1 \\
\hline
\end{tabular}

Table 2. Group2 Concrete Service Life at Various Voltages

\begin{tabular}{|l|c|c|c|}
\hline External voltage [V] & 20 & 12 & 6 \\
\hline Time for reaching critical concentration [d] & 21.86 & 26.61 & 53.76 \\
\hline
\end{tabular}

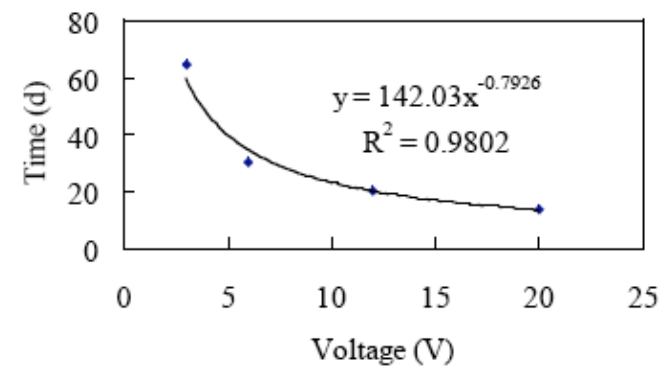

(a) group 1

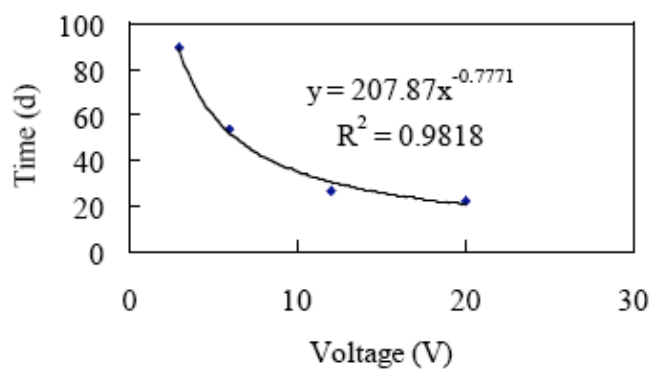

(b) group 2

Fig. (16). Accelerated curve of concrete.

The relationship between external DC voltage and time for reaching critical concentration is made into a diagram, as shown in Fig. (16). From Fig. (16) it can be observed that, in company with decrease of the external voltage, time for reaching critical concentration gradually increases. The accelerated curve of accelerated concrete life prediction can be got after fitting various points in the Figure, and the fitting equation is the service life prediction equation of the mix proportion under the laboratory environment. The differential concentration voltage $4.99 \mathrm{mV}$ mentioned above is substituted into the equation, concluding that the group1 and group2 concrete service life of the mix proportion are 25.97 years and 35.01 years respectively.

In order to verify accuracy of the prediction method and rationality of the model, accelerated permeability test were carried out with the group1 and group2 concrete respectively. In consideration of necessary time of the test, the accelerated permeability test at $20 \mathrm{~V}$ is made to get the change rule of chloride ions at $20 \mathrm{~V}$, calculate the time for reaching the critical concentration and make comparison on the concrete service life at $20 \mathrm{~V}$ calculated on the model.

Group1. Same operators re-mould concrete specimens with the same mixing proportion in the same method. $20 \mathrm{~V}$ is substituted into the service life prediction equation, then the service life is 13.21 days at 20V. Fig. (17) indicates the change rule of chloride ions under the repeatability test of concrete service life at 20V; critical concentration of $0.485 \%$ is substituted into the equation, concluding that the concrete service life is 13.79 days at $20 \mathrm{~V}, 0.58$ day more than 13.21 days, with the deviation ratio of $4.2 \%$, which is small, so the prediction method is considered as a reasonable method with good repeatability.
Group2. Accelerated permeability tests were carried out with the drilled sample of the seawall in Qingdao, the remanent life predicting curve of on-site concrete sample was gotten, shown as in Fig. (18). The differential concentration voltage $4.99 \mathrm{mV}$ is substituted into the equation, concluding that the concrete remanent life is 18.72

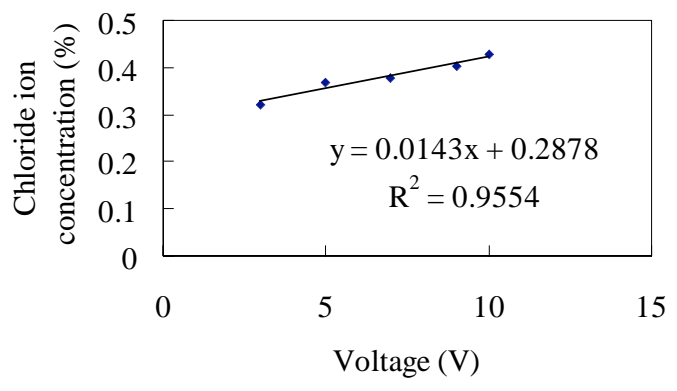

Fig. (17). Accelerated repeatability test of concrete service life at $20 \mathrm{~V}$.

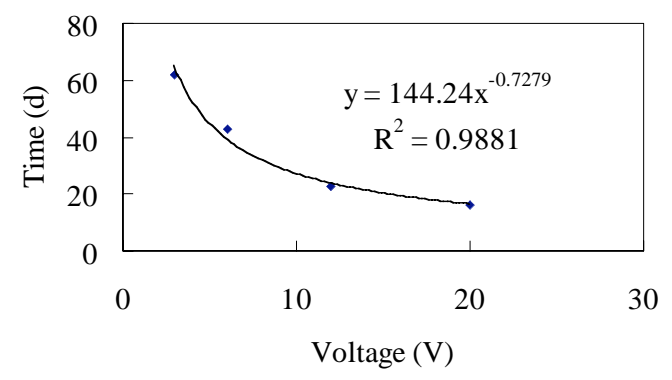

Fig. (18). Accelerated test curve of Qingdao concrete residual service life 
years. As is stated above, the concrete life of groupe 2 is 35.01 year. So based on calculation, the concrete has been in commission for 16.29 years, the difference between calculated result and the fact status is 2.29 years, is so slitht. so the prediction method is considered as a reasonable method with good repeatability.

\section{CONCLUSION}

4.1. In the steel accelerated corrosion test, the chloride ions gathering at the steel surface rapidly under the action of high voltage cause the result that the steel has not depassivated but the chloride ions have exceeded the critical chloride ion concentration of natural permeation. Therefore, the chloride ion contents under higher accelerated voltage are unable to reflect the critical chloride ion concentration value when steel corrodes actually, and proper chloride ion content at a proper voltage shall be selected as the critical chloride ion concentration. Finally, in this test, the critical chloride ion concentration is determined, group $10.485 \%$, group2 $0.461 \%$.

4.2. The concrete service life prediction model is got through the accelerated permeability test, and the concrete service life of group1 and group2 are predicted respectively to be 25.97 years and 35.01years.

After repeatability test at $20 \mathrm{~V}$, the group1 service life at $20 \mathrm{~V}$ is predicted to be 13.21 days, and the repeatability test result is 13.79 days, with the deviation ratio of $4.2 \%$. Accelerated permeability tests were carried out with the drilled sample of the seawall in Qingdao. The concrete was
14 years old in fact, the calculated result was 16.29 years. so it is feasible to adopt the accelerated permeability test to predict the concrete service life.

Mineral admixtures in concrete can protect passivation film of rebar and improve the resistance to corrosion of steel rebar,and decrease the content of free chloride ions due to absorbing or solidifying a large number of free chloride ions in concrete.

\section{REFERENCES}

[1] M. N. S. Hadi, and J. Li, "External reinforcement of high strength concrete columns", Compos. Struct., Vol. 65, pp. 279-287, September 2004.

[2] O. Poupard, V. L'Hostis, S. Catinaud, and I. Petre-Lazar, "Corrosion damage diagnosis of a reinforced concrete beam after 40 years natural exposure in marine environment", Cem. Concr. Res., Vol. 36, pp. 504-520, March 2006.

[3] T. U. Mohammed, N. Otsuki, and H.Hamada, "Corrosion of steel bars in cracked concrete under marine environment", J. Mater. Civ. Eng., Vol. 15, pp. 460-469, September / October 2003.

[4] M. Maage, S. Helland, E. Poulsen, O. Vennesland, and J. E. Carl, "Service life prediction of existing concrete structures exposed to marine environment", ACI Mater. J., Vol. 93, pp. 602-608, November 1996.

[5] Stefan Jacobsen, "Calculating liquid transport into highperformance concrete during wet freeze/thaw", Cem. Concr. Res., Vol. 35, pp. 213-219, February 2005.

[6] Cengiz Duran Atis, "Accelerated carbonation and testing of concrete made with fly ash", Constr. Build. Mater., Vol.17, pp.147152, April 2003.

[7] Khandaker M. and Anwar Hossain, "Chloride induced corrosion of reinforcement in volcanic ash and pumice based blended concrete", Cem. Concr. Compos., Vol. 27, pp.381-390, March 2005. 